\title{
Efficacy of injection of steroids for lateral epicondylitis
}

\author{
R. Maharjan, G. Gurung \\ Department of Orthopaedics, National Academy of Medical Sciences, Bir Hospital, Kathmandu, Nepal.
}

Correspondence to : Dr. Rajram Maharjan, Department of Orthopaedics, National Academy of Medical Sciences, Bir Hospital, Kathmandu, Nepal.

Email: rajram.maharjan@hotmail.com

\begin{abstract}
Introduction: Lateral epicondylitis (Tennis elbow) is one of the most common lesions of the arm. Corticosteroid injection has been described as one of the treatment modalities for this disorder with variable clinical benefit. The purpose of this study was to analyze the short-term and long-term effects of the local injection of methylprednisolone to treat lateral epicondylitis.

Methods: A prospective comparative study was carried out in the Department of Orthopaedics in Bir Hospital from October 2009 to February 2011. Study was undertaken in 40 patients to analyze the short-term and long-term effects of the local injection of methylprednisolone for the treatment of lateral epicondylitis. Twenty patients in each group were included in the study. Patients assigned to experimental group received a single injection of 1 percent lidocaine with forty milligrams of methylprednisolone and control group received a single injection of 1 percent lidocaine with saline solution.

Results: Corticosteroid injection gave better pain relief in a shorter time than the placebo group. Pain was significantly improved in steroid group in comparison to placebo group till third successive follow ups with maximum improvement at eighteen weeks $(\mathrm{p}=0.000)$. However, the groups did not differ with regards to pain at six months as determined with a clinical pain score and visual analogue scale.
\end{abstract}

Conclusions: Local injections of steroids provide rapid pain relief but only short-term benefits in the treatment of lateral epicondylitis.

Key word: Epicondylities, Steroid injection, tennis elbow

\section{Introduction}

Lateral epicondylitis (tennis elbow) was first described in 1873 by Runge, but the name derives from 'Lawn Tennis Arm' described by Morris in 1882. ${ }^{1,2}$ Tennis elbow is one of the most common lesions of the arm. It occurs most commonly between the ages 40 and 60 and usually affects the dominant arm. Its prevalence is said to be from $1 \%$ to $3 \%$ and seems more common in women. ${ }^{3}$ The term 'Tennis elbow' is a too restricted title, it can occur very commonly in patients who have never played tennis. ${ }^{4}$ Lateral epicondilytis is usually defined as a tendinitis of the extensor carpi radialis brevis and occurs in connection with acute or chronic strain. Extensor digitorum communis and extensor carpi radialis longus may also be involved. Despite being first described in 1873, the etiology and treatment are still uncertain. ${ }^{1}$ This pathology is reported more frequently in assembly line workers having to repeat pronationsupination movements than the strength used to do the movement. Epicondilytis may be a misleading term as there is no traditional inflammation. ${ }^{5}$ The histological findings may include granulation tissue, micro rupture and degenerative changes. ${ }^{6,7}$ 
Many treatment modalities have been described for lateral epicondylitis including rest, modification of activity, splints, analgesic and anti-inflammatory drugs, physiotherapy, acupuncture, injections and surgery, have all been investigated and have shown to end up with variable clinical benefit. ${ }^{8}$ Targeting the common extensor origin, various substances have been used for injection treatment, including platelet-rich plasma, autologous blood and corticosteroids. However, the use of a local injection of steroids is controversial. A study conducted in Rheumatology Unit, Guy's Hospital, London in 1991 had shown preference for the use of injections of steroid (triamcinolone) in the initial management of tennis elbow for relief of pain. However, the recurrence of symptoms after initial disappearance of pain has been reported. ${ }^{9}$ Steroid injections have been found to be more effective than physiotherapy. ${ }^{9}$ The incidence of recurrence of symptoms at six months is reported to be high though most patients respond well to injection with corticosteroid preparations initially. ${ }^{10}$

When conservative treatment is unsuccessful, surgical treatment options include a release of the forearm extensor muscles from the epicondyle and divisions of the branches of the radial nerve are performed. ${ }^{11,12}$

This study was undertaken to analyze the short-term and long term effects of the local injection of steroids in comparison to normal saline to treat lateral epicondylities.

\section{Methods}

Forty patients who attended outpatient department of Bir hospital with lateral epicondylitis were assigned to the study from October 2010 to August 2010. Twenty three patients were women and seventeen patients were men, with a mean age of 44.6 years (age range 38-65) and mean time of symptoms of 2.5 months (range 1.5-6 months). Seventeen patients were farmers, twelve patients were manual laborers, five were non professional athletes and six had a job that seldom involved the performance of strenuous duties. The ethical clearance for this study was taken from Institutional Review Board (IRB), National Academy of Medical Sciences (NAMS) and every patient gave informed consent.

The criteria for entry were pain on the lateral side of the elbow, tenderness over the forearm extensor origin, and pain on the lateral epicondyle during resisted dorsiflexion of the wrist with the elbow in full extension. Patients were excluded if they had had a previous operation on the lateral side of the elbow, or had arthritis or allied conditions, neurological disorders of the painful extremity (such as the cervical root compression syndrome and compression of the posterior interosseous branch of the radial nerve, ulnar neuropathy), an injury of the elbow, carpal tunnel syndrome, medial epicondylitis, or pregnancy and age under eighteen years and above sixty five years. Patients treated with local corticosteroid injections in the past and the treatment of same elbow before by any other modalities except physiotherapy was also excluded from the study. In those with bilateral symptoms only the most painful arm was included. Patients who fulfilled the criteria were divided in two treatment groups according to the predetermined randomization schedule; steroid group or placebo group.

Steroid treatment group consisted of twenty elbows that were treated with one injection of forty milligrams of methylprednisolone (one milliliter) with one milliliter of 1 per cent lidocaine. Placebo treatment group consisted of twenty elbows that were treated with one injection of one milliliter of 1 per cent lidocaine with one milliliter of saline solution $(0.9$ per cent $\mathrm{NaCl})$. Thus, the total volume of solution that was injected was identical for the two groups, eliminating differences due to distention of tissues. The injection was administered with a standard 22-gauge needle into the tenderest area at the tendinous origin of the extensor digitorum and extensor carpi radialis brevis muscles. The patients were seen at six week, three month, eighteen weeks and six month after the start of treatment and all patients were also asked to visit as early as possible if injection related complications appeared.

All forty patients were treated according to a standard protocol consisting of the use of non-steroidal antiinflammatory medications (ie. Aceclofenac $100 \mathrm{mg}$ twice daily for 5 days), elimination of activities that provoked pain and physical therapy following injections. The outcome was, compared with the pre-treatment condition. As pain is considered to be the major indication for operative treatment whenever non-operative treatment has failed, the patients were asked to use a visual analogue scales to record their subjective assessment of pain ranging from 0 to 10 with 0 representing no pain and 10 the worst pain they had ever experienced. Additionally, clinical findings were documented with the use of a clinical pain score (Table 1). ${ }^{13}$ The highest possible pain score-i.e., for the most severe disease-was 10 points, and a minimum of 4 points was necessary to be included in the study. Hence, the evaluation of the intensity of pain was the only additional criterion used to estimate the beneficial effects of the treatment modalities in the present study. 
Table 1: Clinical pain score

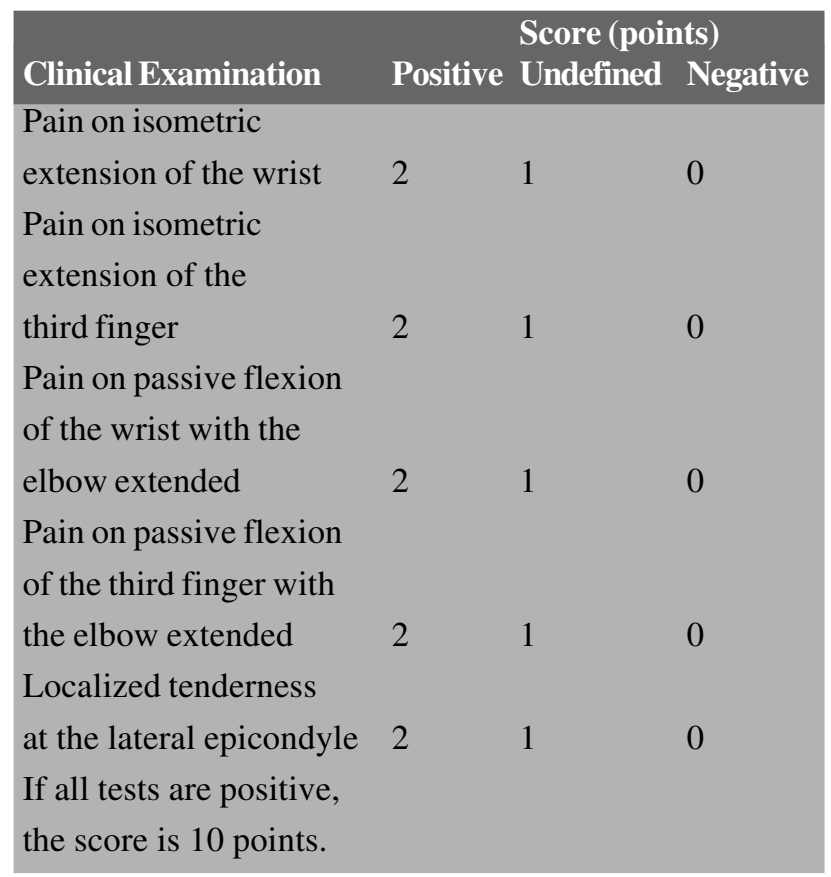

\section{Results}

Overall, 40 patients were included in the treatment phase of the study and were randomly assigned to receive either steroid group (twenty patients) or a placebo group (twenty patients). None of the patients dropped out of the study during the six month of follow-ups. The median duration of the disease prior to inclusion in the study was 2.5 months in the total patient population. The overall period of recruitment lasted from October 2009 to August 2010. The follow-up was completed in February 2011. All the patients were followed up regularly at six weeks, three months, eighteen weeks and six months.

Twenty patients ( 12 women and 8 men with an average age of 45.4years) treated with methylprednisolone with xylocaine injection and twenty patients (11 women and 9 men with an average age of 43.9 years) treated with $0.9 \% \mathrm{NaCl}$ with xylocaine injection in the placebo group completed the study $(n=40)$. The difference in age and sex distribution was not significant. The age of the patients was ranged from 38 to 65 years. Out of 40 patients, 27 patients had right sided and 13 patients had left sided tennis elbow ( $\mathrm{p}=0.096)$. Right was the dominant hand in all patients. In steroid group, 12 patients had right sided tennis elbow and 8 patients had left sided tennis elbow while in placebo group, 15 patients had right sided and 5 patients had left sided tennis elbow (Table 2).
Table 2: Characteristics of patients

$\begin{array}{llll} & \begin{array}{l}\text { Experimental } \\ \text { Group }\end{array} & \begin{array}{l}\text { Control Difference } \\ \text { Group }\end{array} & \begin{array}{l}\text { between } \\ \text { Groups }\end{array} \\ \text { Total no. of elbows } & 20 & 20 & \text { NS } \\ \text { In male patients } & 8 & 9 & \text { NS } \\ \text { In female patients } & 12 & 11 & \text { NS } \\ \text { No. of dominant } & & & \\ \text { limbs involved } & 12 & 15 & \text { NS }\end{array}$

NS = not significant.

For the subjective evaluation, clinical pain score that was used in a study done by Placzek et al. was used (Table 1). In the group treated with steroid, the clinical pain score showed significant improvement, compared with the score in the placebo group till third successive follow ups $(\mathrm{p}=0.000)$, with maximum improvement from a pretreatment level of 3.90 to 1.05 at eighteen week. But the clinical pain score in steroid group increased to 1.55 at the end of sixth month follow-up. The difference in clinical pain scores between two groups was not significant ( $\mathrm{p}=0.161)$ (Fig 1). Similarly, the visual analogue scores was also significantly improved in steroid group in comparison to the placebo group from the sixth week onward to eighteen weeks $(p=0.00)$, but it was increased to 3.80 at the end of sixth month which was not significant between two groups ( $\mathrm{p}=0.858)$ (Fig 2).

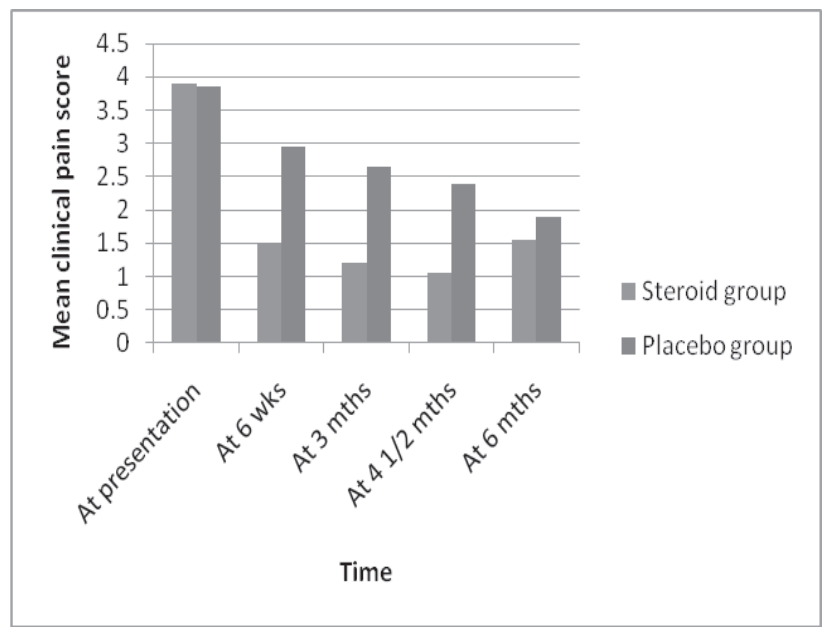

Fig. 1: Clinical pain score

The clinical pain score was significantly improved in the experimental group (steroid) than in the control group (nonsteroid) till $4 \frac{1}{2} 2$ month follow up after the injection ( $\left.\mathrm{p}=0.000\right)$ (Fig. 1). No significant differences were found between the groups before the injection $(\mathrm{p}=0.861)$ and at the end of 6 month after the injection $(0.161)$. 


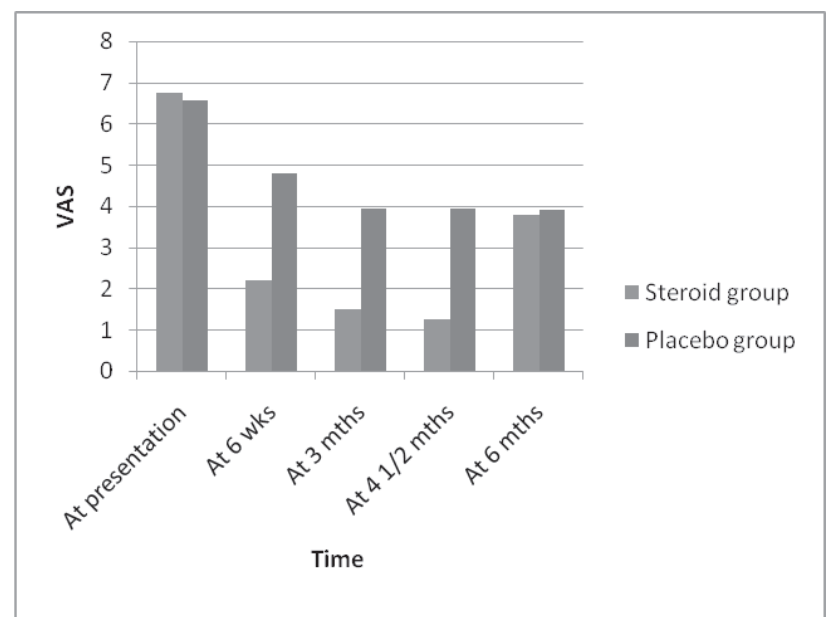

Fig. 2: Bar graph showing the mean scores on the visualanalog scale for the intensity of pain.

The visual analog score was significantly lower in the experimental group (steroid) than in the control group (nonsteroid) till $4 \frac{1}{2} 2$ month follow up after the injection ( $\left.\mathrm{p}=0.000\right)$. The scores were similar in the two groups before the injection ( $\mathrm{p}=0.373)$ and at the end of 6 month after the injection (0.858) (Fig.2).

No local complications could be attributed to the injection of methylprednisolone; however, swelling and pain were complained by all patients at the injected site which were subsided within forty- eight hours to seventy-two hours after injection.

\section{Discussion}

The primary abnormality of lateral epicondylitis involves the origin of the extensor carpi radialis brevis, and less commonly the anterior aspect of the extensor digitorum tendon. ${ }^{13}$ The cause is generally considered to be repetitive microtrauma sustained during supination of the forearm and dorsiflexion of the wrist. Repetitive microtrauma results in tendon degeneration. A chronic cycle of tendon degeneration and repair ensues, with weakening of the common extensor origin and with potential for rupture. Histopathological correlation of tennis elbow demonstrated disrupted collagen fibres, increased cellularity and neovascularisation in the common extensor tendons. ${ }^{14,15}$

Although tennis elbow is a self-limiting disease, about onequarter have recurrent symptoms. More than $40 \%$ of patients have been reported to have limitations of particular activities due to persistent pain. ${ }^{16}$ Therefore, many treatment modalities have been described for lateral epicondylitis from rest to injection of various substances (steroids, botulinum, autologous blood etc.) often used on the basis of personal experience and preference rather than the demonstrated superiority of one treatment over another. When conservative treatment is unsuccessful, surgical treatment options include a release of the forearm extensor muscles from the epicondyle and division of the branches of the radial nerve. ${ }^{13}$ The result is often gratifying, but sometimes surgery is the beginning of an unfavorable clinical course. ${ }^{17}$

In our study both local corticosteroid injection and placebo groups showed continuous improvement in the pain scores, but the improvement was less pronounced in placebo group as compared to corticosteroid injection. Corticosteroid injection gave better pain relief in a shorter time than the placebo group. Pain was significantly improved in steroid group in relation to placebo group in all successive follow ups $(\mathrm{p}=0.000)$ with maximaum improvement at eighteen weeks. Our results are comparable with those of Crowther $\mathrm{M}$ et al. ${ }^{7}$ There is recurrence of pain in significant numbers of patients at six month in the corticosteroid injection group with a mean VAS score from a pretreatment level of 6.75 to 3.80. So, at the end of six month the pain between two groups was not significant $(\mathrm{p}=0.858)$. It can be believed that this improvement primarily reflects the natural course of lateral epicondylitis and the therapeutic effects of physical therapy and non-steroidal anti-inflammatory medications. There is recurrence of pain at six month in the steroid group with other observations. ${ }^{18,19,20,21}$ As all patients were managed with non-steroidal anti-inflammatory medications and physical therapy in addition to the injection of the steroid, the precise effectiveness of the injection in both groups might be questionable. However, all patients were managed in the same physical therapy department according to very similar protocols. In addition to these therapeutic measures, improvement was less pronounced in placebo group as compared to corticosteroid injection till third follow up $(\mathrm{p}=$ 0.000). Thus, any observed differences should be attributed only to the pharmacological effects of the steroid. Thus, corticosteroid injections may alleviate the pain in tennis elbow very well, but may not address the cause.

\section{Conclusions}

The local injection of a steroid has only short-term beneficial effects in the treatment of tennis elbow. Non invasive other therapeutic modalities such as rest, physical therapy, and the use of non-steroidal anti- inflammatory medications, are probably the best ways to treat this clinical entity. 


\section{References}

1. Runge F. Zur Genese und Behandlung des Schreibekrampfes. Berliner klin. Wochenschr. 1873;10:245-8.

2. Morris H. The rider's sprain. Lancet 1882;29:133-4.

3. Thurston AJ. Conservative and surgical treatment of tennis elbow: a study of outcome. Aust. N.Z. J. Surg. (1998); 68:568-72.

4. Alfredson $\mathrm{H}$, Ljung $\mathrm{BO}$, Thorsen $\mathrm{K}$. In vivo investigation of ECRB tendons with microdialysis technique-no signs of inflammation but high amounts of glutamate in tennis elbow. Acta Orthop Scand 2000;71:475-9.

5. Nirschl RP .Elbow tendinosis/tennis elbow. Clin Sports Med 1992;11:851-70.

6. Regan W, Wold LE, Coonrad R. Microscopic histopathology of chronic refractory lateral epicondylitis. Am J Sports Med 1992;20:746-9.

7. Crowther MAA, Bannister GC. Huma H, Rooker GD. A prospective, randomised study to compare extracorporeal shock-wave therapy and injection of steroid for the treatment of tennis elbow. J Bone Joint Surg [Br] 2002;84-B:678-9.

8. Price R, Sinclair H, Heinrich I, Gibson T. Local injection treatment of tennis elbow: hydrocortisone, triamcinolone and lignocaine compared. $\mathrm{Br} \mathrm{J}$ Rheumatol 1991;30:39-44.

9. Verhaar JA, Wakenkamp GH, van Mameren H, Kester $\mathrm{AD}$, van der Linden AJ. Local corticosteroid injection versus Cyriax-type physiotherapy for tennis elbow. J Bone Joint Surg [Br] 1996;78-B:128-32.

10. Clarke AK, and Woodland J. Comparison of two steroid preparations used to treat tennis elbow, using the Hypospray. Rheumatol. Rehabil.,14,4749.

11. Hohmann LGH. Das Wesen und die Behandlung des sogenannten Tennisellenbogens. Münch Med Wochenschr. 1933;80:250-2.

12. Nirschl RP, Pettrone FA. Tennis elbow. The surgical treatment of lateral epicondylitis. J Bone Joint Surg Am. 1979;61:832-9.

13. Wilhelm A, Gieseler H. [Treatment of radiohumeral epicondylitis by denervation]. Chirurg. 1962;33:11822. German.

14. Goguin JP and Rush F Lateral epicondylitis. What is it really? Current Orthopaedics (2003); 17: 386—9.

15. Placzek R, Drescher W, Deuretzbacher G, Hempfing A and Meiss L. Treatment of Chronic Radial Epicondylitis with Botulinum Toxin A. A Double-Blind, Placebo-Controlled, Randomized Multicenter Study J Bone Joint Surg Am. 2007;89:255-60.

16. Connell D, Burke F, Coombes P, McNealy S, Freeman D, Pryde D, Hoy G. Sonographic examination of lateral epicondylitis. Am J Roentgenol 2001;176:777-82.

17. Nirschl RP, Pettrone FA. Tennis elbow: the surgical treatment of lateral epicondylitis.J Bone Joint Surg Am 1979;61:832-9.

18. Kraushaar BS, Nirschl RP. Tendinosis of the elbow (Tennis Elbow). Clinical features and findings of histological, immunohistochemical and electron microscopy studies. J Bone Joint Surg Am 1999;81: 269-78.

19. Binder AI, Hazleman BL. Lateral humeral epicondylitis - a study of natural history and the effect of conservative therapy. Br J Rheumatol. 1983;22: 73-6.

20. Kalainov DM, Cohen MS. Posterolateral rotatory instability of the elbow in association with lateral epicondylitis. A report of three cases. J Bone Joint Surg Am. 2005;87:1120-5.

21. Day BH, Govindasamy N, Patnaik R. Corticosteroid injections in the treatment of tennis elbow. Practitioner 1978;220:459-62.

22. Clarke AK, Woodland J. Comparison of two steroid preparations used to treat tennis elbow using the hypospray. Rheumatol Rehabil 1975;14:47-9.

23. Nevelos AB. The treatment of tennis elbow with triamcinolone acetonide. Curr Med Res Opin 1980;6:507-9.

24. Smidt N, Assendelft WJ, van der Windt DA, Hay EM, Buchbinder R, Bouter LM. Corticosteroid injections for lateral epicondylitis: a systematic review. Pain. 2002;Mar;96(1-2):23-40. 